\title{
Interaction of Factors Influencing the Sustainability of Water, Sanitation, and Hygiene (WASH) Services in Rural Indonesia: Evidence from Small Surveys of WASH-Related Stakeholders in Indonesia
}

\author{
D. Daniel ${ }^{1,2, *} \mathbb{C}$, Dennis Djohan ${ }^{1}$ and Anindrya Nastiti ${ }^{3}$
}

1 Department of Water Management, Faculty of Civil Engineering and Geosciences, Delft University of Technology, 2628 CN Delft, The Netherlands; DennisDjohan@student.tudelft.nl

2 Department of Health Behavior, Environment, and Social Medicine, Faculty of Medicine, Public Health and Nursing, Universitas Gadjah Mada, 55281 Yogyakarta, Indonesia

3 Environmental Management Technology Research Group, Faculty of Civil and Environmental Engineering, Bandung Institute of Technology, 40132 Bandung, Indonesia; anindrya@tl.itb.ac.id

* Correspondence: d.daniel@tudelft.nl or danielhombing@gmail.com

Citation: Daniel, D; Djohan, D.; Nastiti, A. Interaction of Factors Influencing the Sustainability of Water, Sanitation, and Hygiene (WASH) Services in Rural Indonesia: Evidence from Small Surveys of WASH-Related Stakeholders in Indonesia. Water 2021, 13, 314. https://doi.org/10.3390/w13030314

Academic Editor: Guy Howard

Received: 7 January 2021

Accepted: 22 January 2021

Published: 27 January 2021

Publisher's Note: MDPI stays neutral with regard to jurisdictional claims in published maps and institutional affiliations.

Copyright: (c) 2021 by the authors. Licensee MDPI, Basel, Switzerland. This article is an open access article distributed under the terms and conditions of the Creative Commons Attribution (CC BY) license (https:/ / creativecommons.org/licenses/by/ $4.0 /)$.

\begin{abstract}
It is argued that there are interconnected and dynamic factors that influence the sustainability of water, sanitation, and hygiene (WASH) services in developing countries. Five sustainability factors are often mentioned by literature: financial, institutional, environmental, technical, and social (FIETS) factors. This article aims to understand the interaction of those five sustainability factors in the context of WASH services in Indonesia. A system approach, in the form of a "modified" causal loop diagram, was utilized to analyze this interaction. The strength of influence from one factor to others were obtained from small surveys of $16 \mathrm{WASH}$ practitioners and experts from international and national non-governmental organizations (NGOs) based in Indonesia and national government institutions related to WASH. It was found that institutional factor is the "leverage" factor, i.e., the most influential and least dependent, in the WASH services system in Indonesia. It means that WASH institutional strengthening is necessary to sustain WASH services in Indonesia. Furthermore, the most important feedback loop is social-WASH services. This depicts the importance of the bi-directional effect of WASH services and the social conditions of the community, i.e., the more supportive the community is, the higher the likelihood of the sustainability of WASH services, and then positively influence back the social conditions of the community. Moreover, the relationship between factors varies across context or location. Finally, this paper shows that the sustainability of WASH services involves complex interactions of the sustainability factors and understanding these interactions is critical to sustaining the WASH services or program in rural Indonesia.
\end{abstract}

Keywords: water; sanitation; sustainability; causal loop diagram; Indonesia

\section{Introduction}

There is a high concern for the sustainability of water, sanitation, and hygiene (WASH) services, such as provision of water supply and sanitation services, in developing countries. Sustainability in the WASH services means that the WASH services remain functional, even after the WASH implementer organization leaves that place [1,2]. Previous reports mentioned that many WASH services failed, especially in rural areas, water supply [3-5] or sanitation services [6-8]. Therefore, a lot of investment is wasted due to this problem. For example, it was estimated that the WASH system failure in Africa resulted in a lost investment of $\$ 1.2$ billion [9]. Furthermore, unsustainable WASH services inhibit the progress of the UN Sustainable Development Goals 6, i.e., achieving 100\% access to safely managed water and sanitation services. 
Indonesia is one of the developing countries struggling to achieve $100 \%$ access to sustainable water and sanitation services. Inequalities of WASH services between different regions is also an issue [10]. Despite the significant progress over the last 20 years in Indonesia, i.e., reduction of open defecation by more than $20 \%$ and increasing of access to basic water services by about $15 \%$ [11], there are still many challenges to expand and sustain the services, such as financial and institutional support [12,13].

Numerous sustainability frameworks have been introduced and used to improve WASH services [14]. One of the frameworks is FIETS, which was introduced by the Dutch WASH Alliance (DWA) [15]. FIETS stands for financial, institutional, environmental, techni$\mathrm{cal}$, and social. Financial could be defined as self-ability to support the costs associated with the WASH services, e.g., operational and maintenance costs, repairs costs, etc. Institutional is related to the overall performance of the institutions (e.g., municipality, village office, water board, etc.) to execute/monitor/maintain the WASH services. Environmental refers to environmental services that continually deliver or support the WASH services, e.g., topography, groundwater availability, soil structure, weather, etc. Technical is related to the WASH technology and the ability to perform related technical matters, e.g., able to obtain, operate and maintain the WASH-related technologies, such as a latrine, water filtration, water pump, etc. Social is the related social conditions of the community to sustain the WASH services or program, e.g., level of awareness, level of community participation, WASH-related behaviour, etc.

It is believed that WASH services will sustain in the long term if these five sustainability aspects or factors are well addressed in the WASH program. FIETS framework was used in this study because it has been used widely in Indonesia, i.e., the WASH-related stakeholders are familiar with the framework. Examples of WASH-related stakeholders who use FIETS frameworks are the community-based drinking water supply and sanitation program, so-called PAMSIMAS in Bahasa [16] and WASH non-governmental organizations (NGO) in Indonesia [17].

However, Valcourt et al. [18] argue that the sustainability of WASH services is influenced by the interactions between the sustainability factors and not only by the individual, e.g., institutional only, or accumulation of influence of the individual sustainability factors, e.g., institutional plus financial. This highlights the importance of analyzing the interactions between these sustainability factors, i.e., FIETS.

To the best of our knowledge, there is no study discussed what sustainability factor(s) is/are critical to sustaining WASH services in Indonesia and how these sustainability factors influence each other. Therefore, the objective of this study is to assess the dynamic influence between the FIETS sustainability factors and WASH services in the context of Indonesia. Furthermore, we also seek to find the leverage factor, i.e., the most important sustainability factor that should get the first priority to sustain WASH services in Indonesia. We then discussed the findings and related them with previous studies in developing countries. Finally, this study also contributed to the growing body of literature on the application of a system approach in WASH domain, especially in Indonesia.

\section{Materials and Methods}

\subsection{Data Collection}

Sixteen WASH practitioners and experts from international and national nongovernmental organizations (NGOs) based in Indonesia and national government institutions related to WASH were involved in this study. Of these 16 respondents, 8 were from WASH-related NGOs, 3 were WASH consultants, 2 were governmental bodies, one person was a WASH-related private company or industry, and two were WASH researchers. All respondents were chosen based on experiences in the WASH sectors in Indonesia for about ten years. Only one respondent was not native but has more than ten years of experience in the WASH sector in Indonesia. They were asked to fill a questionnaire consisting of questions about the strength of influence of one factor on the others. For example, the first question asks about the influence of a variable "sustainability of WASH services" on 
all five FIETS factors and the second question asks about the influence of "financial" on the other four factors and the variable "sustainability of WASH services". The strength of influence was measured by scores " -3 " to " +3 ", in which negative or positive sign indicate the polarity of influence, i.e., the negative sign means that if variable A increases (the cause variable), then the affected variable $B$ will decrease, and vice versa for a positive sign. Value " 3 " means that the influence is very strong, " 2 " means that the influence is moderate, and " 1 " means that the influence is "weak". A value " 0 " means that there is no direct influence from variable A to B. For example, if one of the experts gives a value of " +3 " from financial to "sustainability of WASH services", it means that, according to that expert, the influence of financial on the sustainability of WASH services is very strong and positive, i.e., if the financial condition is good, it will support positively the WASH services.

\subsection{Data Analysis}

Normally, in a regional project, different experts and local stakeholders can discuss their disagreement in a workshop and come up to a consensus, as shown in Valcourt et al. [18]. However, in our case, the strength of influence of each factor was averaged over the 16 respondents to obtain the composite data. The polarity for each factor strength was included when calculating the average. The composite causal strengths were then laid out onto a cross-impact matrix. In this matrix, the influencing factors were arranged in each row and the influence value was inserted across the columns. Further, to find which factor(s) are the most influential or dependent, the connection values on the cross-impact matrix were summed along the row/column to find the total influence/dependence for each factor, respectively.

Once the total influence and dependence of each factor have been identified, they were categorized by mapping them into the influence map [19]. The influence map was created by plotting the total influence against the total dependence for each factor. The plot scales from the lowest to the highest possible value, which in this case is 0 to 18 since there are 6 factors with a maximum value of 3 for each. The map is divided into 4 quadrants at the midpoint of influence and dependence. The quadrant 1 (Q1) lies at the high end of both influence and dependence. The factors present in this quadrant are unstable. They carry a large impact on the system while at the same time vulnerable to changes caused by other factors. When a factor has a high influence but low dependence it is put into quadrant 2 (Q2). This is called the "leverage factor". Contrary to factors in Q1, the "leverage factors" are stable while also being an influential driver within the system. Factors in quadrant 3 (Q3) and 4 (Q4) are considered not influential to the system. The factors in Q3 are not dependent on the other factors but the ones in Q4 are highly dependent, i.e., influenced much by other factors. When a factor lies in the boundary between the quadrants it is considered to be able to go either way.

The data from the cross-impact matrix was used to create the Causal Loop Diagram (CLD) and identify the loop strength for each feedback loop. The CLD is a qualitative aspect of the system dynamics modeling that portrays the cause-effect relationship of factors in a system [20]. Vensim Pro software package [21] was used to create the CLD. Then the normalized feedback loop strength is calculated by adding all the connection strength and dividing it by the number of connections in the loop [22]. An example of a WASH $\rightarrow$ Social $\rightarrow$ Institution $\rightarrow$ WASH loop strength calculation is shown below.

$$
\frac{\sum_{i=1}^{n}\left(\text { Cause Factor } \rightarrow{\text { Effect Factor })_{i}}\right.}{n}=\frac{3+2+3}{3}=2.67
$$

Once calculated, the feedback loops are sorted by their strength to identify the crucial loops. The most important loops were then discussed. 


\section{Results}

\subsection{Questionnaire Results}

Figure 1 shows an overview of the distribution. The $x$-axes show the influence direction, and the y-axes show the strength and polarity of the connection. For example, "Fin - WASH" signifies the influence of financial factor on the WASH condition. The box plots show that there are disagreements with the polarity and the influence strengths between the respondents. The influence of five FIETS factors towards WASH has the least variation and leans towards the strong end of the positive spectrum. This displays the consensus among respondents that each of the five FIETS factors positively drives the sustainability of WASH services, e.g., if there is a strong financial aspect, there will be a strong positive drive towards a sustainable WASH services. This result also suggests the need for a holistic or integrated approach to improve all five FIETS factors or aspects and not only focus on one factor. On the other hand, the influence towards social factor has the most variation which could be because the respondents have diverse cultural experiences.
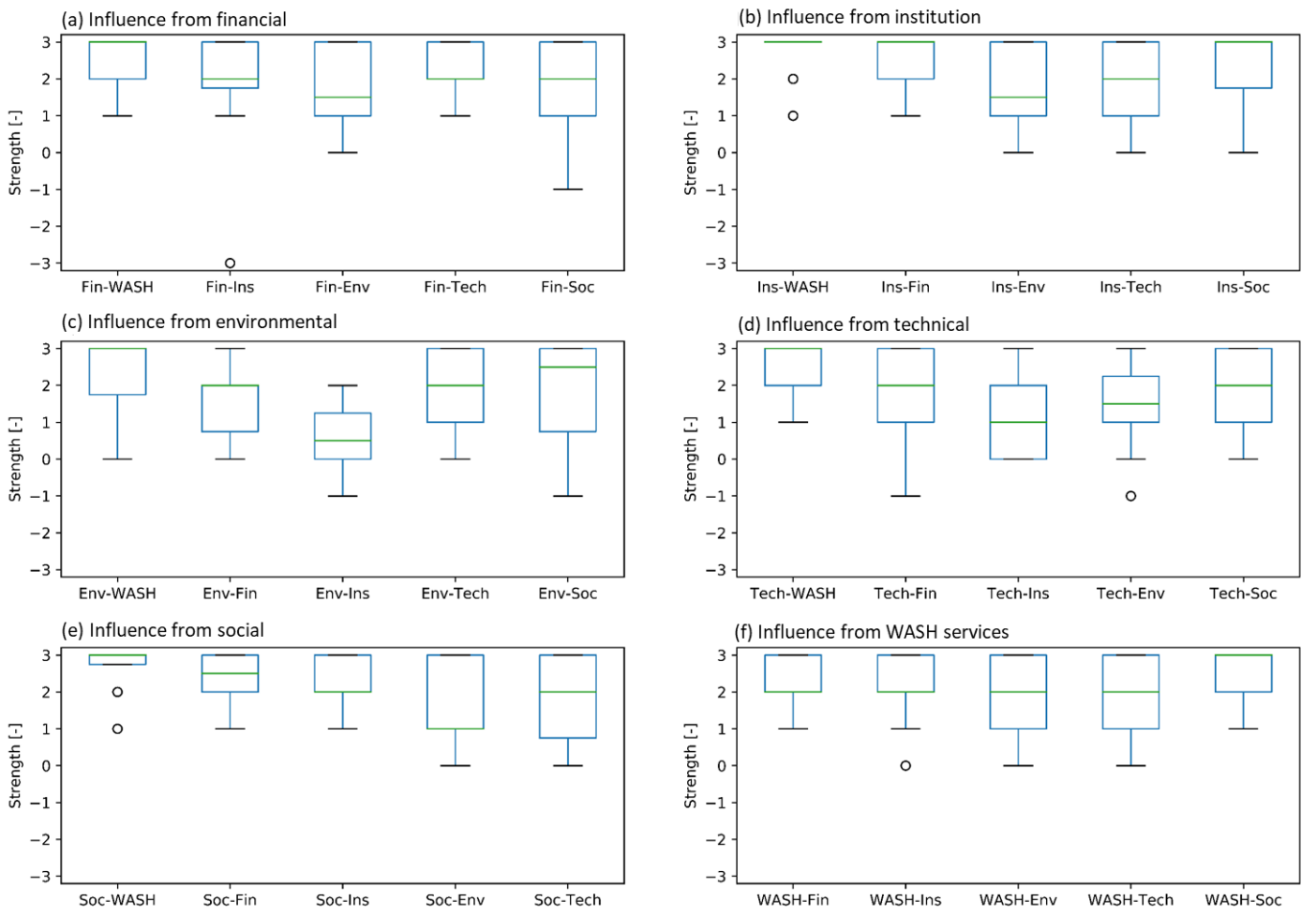

Figure 1. Response distribution from the respondents shown through box plots, e.g., "Fin — Ins" means the influence from financial to institutional. The green line is the median and the dot is a single data point.

The box plots also indicate that there is a variation among respondents regarding influence and polarity in several factors, notably the Financial - Social, Environmental Institutional, Environmental - Social, Technical - Financial, and Technical - Environmental. The most evident one is from the financial aspect to the institutional aspect in which there is one expert argued that better financial condition can weaken the institutional foundation within the system.

\subsection{Causal Relationship Analysis}

Table 1 shows the cross-impact matrix. The polarity for every causal connection is positive, which means that on average all feedback loops present in the system are reinforcing loops, i.e., positive influence. This implies that improving one factor will improve others and then the whole system. The most influential factors are tied between institutional, social, and WASH. The most dependent factor is WASH followed by social 
factor. Additionally, among all FIETS factors, social factor is the one most influenced by WASH services, i.e., score " +3 ", while influences of WASH services on other factors are "+2".

Table 1. The cross-impact matrix. The influencing factors are shown in the first column on the left and the affected factors are shown in the first row.

\begin{tabular}{cccccccc}
\hline Factor & Financial & Institutional & Environmental & Technical & Social & WASH Services * & Influence \\
\hline Financial & & 2 & 2 & 2 & 2 & 2 & 10 \\
Institutional & 2 & & 2 & 2 & 2 & 2 & 2 \\
Environmental & 1 & 1 & & 2 & 2 & 3 & 3 \\
Technical & 2 & 1 & 2 & 2 & & 11 \\
Social & 2 & 2 & 2 & 2 & 3 & 11 \\
WASH services & 2 & 2 & 2 & 10 & 11 & 13 \\
\hline Dependence & 9 & 8 & *WASH services: water, sanitation, and hygiene services, e.g., water supply or sanitation services.
\end{tabular}

Figure 2 shows the position of each factor in an influence map. This information helps in determining the characteristics of each factor and which one should be tackled first to improve WASH implementations. While it was found that institutional, social, and WASH are tied as the most influential factors, only the institutional factor is considered the leverage factor as it is the least dependent on the other factor. At the early stage of a project, institutions should be the first aspect that should be tackled since it is stable and once improved it can help to drive the system towards a sustainable WASH practice. Table 1 also shows that financial and social aspects heavily influenced institutions among other sustainability factors, implying that improvement in financial and social factors will improve the institutional aspect.

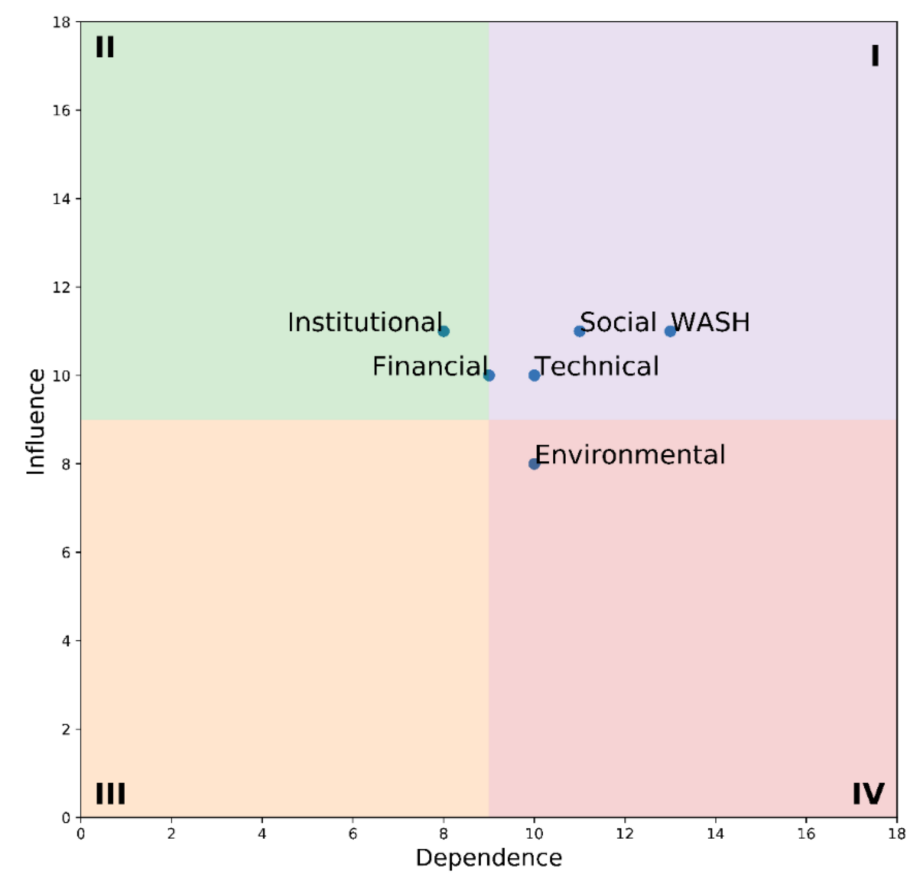

Figure 2. Influence-dependence map from the cross-impact matrix.

Another aspect to be considered as the leverage factor is the financial factor as it lies at the boundary between Q1 and Q2, suggesting that financial factor should be not taken lightly to sustain the WASH services. Social, technical, and WASH factors can be worked on once the institutional and financial situations have been improved. Lastly, the environmental element is the least influential but dependent on the other factors. It should become better when the other factors are improving. 
The information from the cross-impact matrix is used in Vensim to visualize the connections present in the WASH system (Figure 3). Vensim identified 325 feedback loops involving WASH services within the loop. Two variables loop are located mostly at the top in terms of strength, however, they only account for $1.5 \%$ of the total loops. On the other hand, there are more loops with a higher number of variables or factors in the loop, i.e., three, four, five, and six variables loops represent $6.2 \%, 18.5 \%, 36.9 \%$, and $36.9 \%$ of the system, respectively. It is therefore imperative that the sustainability of WASH services involve a complex interaction of the sustainability factors.

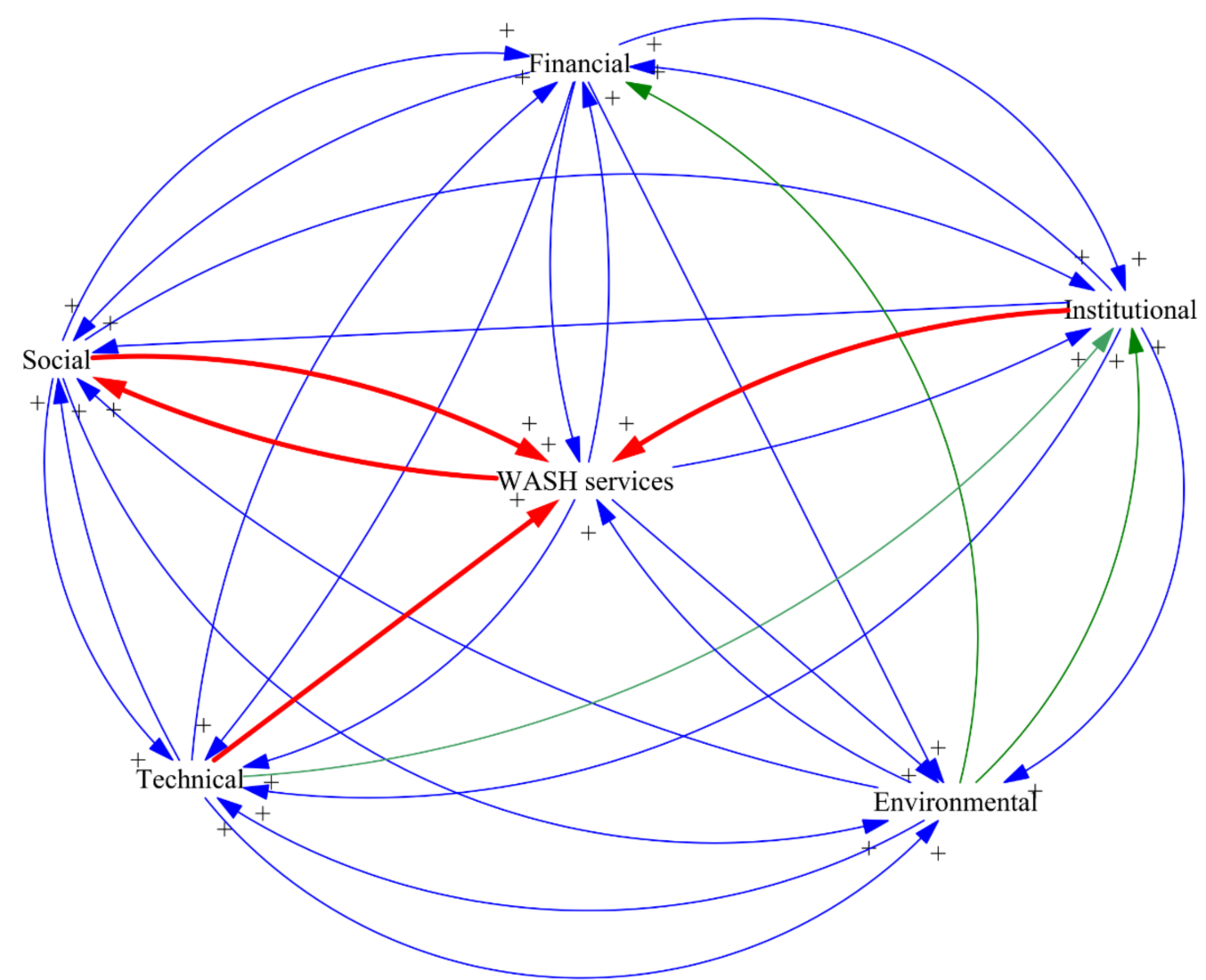

Figure 3. Causal Loop Diagram (CLD). The arrow shows the direction of the influence. The positive correlation is shown by (+) sign near the arrowhead. Red, blue, and green lines represent influence strength 3,2 , and 1 , respectively.

Table 2 shows the top five ranks of the strongest feedback loops identified in the system based on the calculation using equation 1 . The strongest feedback loop is WASH services Social (or Social - WASH services) with a loop strength of 3.00. The second strongest loops are tied with a loop strength of 2.67 between WASH services - Social - Institutional and WASH services - Social - Technical. Figure 4 shows the combination of these three loops signifying the most important drivers in the system. Table 2 lists some of the sorted loops for comparison. The majority are not far behind, from the rank 1 and 2 loops. 
Table 2. Sorted feedback loop based on loop strength. Variable 1-6 columns field shows the factors present within the loop.

\begin{tabular}{|c|c|c|c|c|c|c|c|}
\hline \multirow[b]{2}{*}{ Rank } & \multicolumn{6}{|c|}{ Feedback Loop } & \multirow{2}{*}{$\begin{array}{c}\text { Loop } \\
\text { Strength }\end{array}$} \\
\hline & Factor 1 & Factor 2 & Factor 3 & Factor 4 & Factor 5 & Factor 6 & \\
\hline 1 & WASH services & Social & & & & & 3.00 \\
\hline 2 & WASH services & Social & Institutional & & & & 2.67 \\
\hline 2 & WASH services & Social & Technical & & & & 2.67 \\
\hline 3 & WASH services & Technical & & & & & 2.50 \\
\hline 3 & WASH services & Social & Financial & Institutional & & & 2.50 \\
\hline 3 & WASH services & Social & Environmental & Technical & & & 2.50 \\
\hline 3 & WASH services & Social & Institutional & Technical & & & 2.50 \\
\hline 3 & WASH services & Social & Financial & Technical & & & 2.50 \\
\hline 3 & WASH services & Institutional & & & & & 2.50 \\
\hline 4 & WASH services & Social & Technical & Financial & Institutional & & 2.40 \\
\hline 4 & WASH services & Social & Institutional & Financial & Technical & & 2.40 \\
\hline 4 & WASH services & Social & Financial & Institutional & Technical & & 2.40 \\
\hline 4 & WASH services & Social & Institutional & Environmental & Technical & & 2.40 \\
\hline 4 & WASH services & Social & Financial & Environmental & Technical & & 2.40 \\
\hline 5 & WASH services & Technical & Social & & & & 2.33 \\
\hline 5 & WASH services & Social & Financial & Institutional & Environmental & Technical & 2.33 \\
\hline 5 & WASH services & Social & Environmental & & & & 2.33 \\
\hline 5 & WASH services & Financial & Institutional & & & & 2.33 \\
\hline 5 & WASH services & Financial & Technical & & & & 2.33 \\
\hline 5 & WASH services & Social & Institutional & Financial & Environmental & Technical & 2.33 \\
\hline 5 & WASH services & Environmental & Technical & & & & 2.33 \\
\hline 5 & WASH services & Social & Environmental & Technical & Financial & Institutional & 2.33 \\
\hline 5 & WASH services & Financial & Social & & & & 2.33 \\
\hline 5 & WASH services & Environmental & Social & & & & 2.33 \\
\hline 5 & WASH services & Social & Financial & & & & 2.33 \\
\hline 5 & WASH services & Institutional & Technical & & & & 2.33 \\
\hline 5 & WASH services & Institutional & Social & & & & 2.33 \\
\hline
\end{tabular}

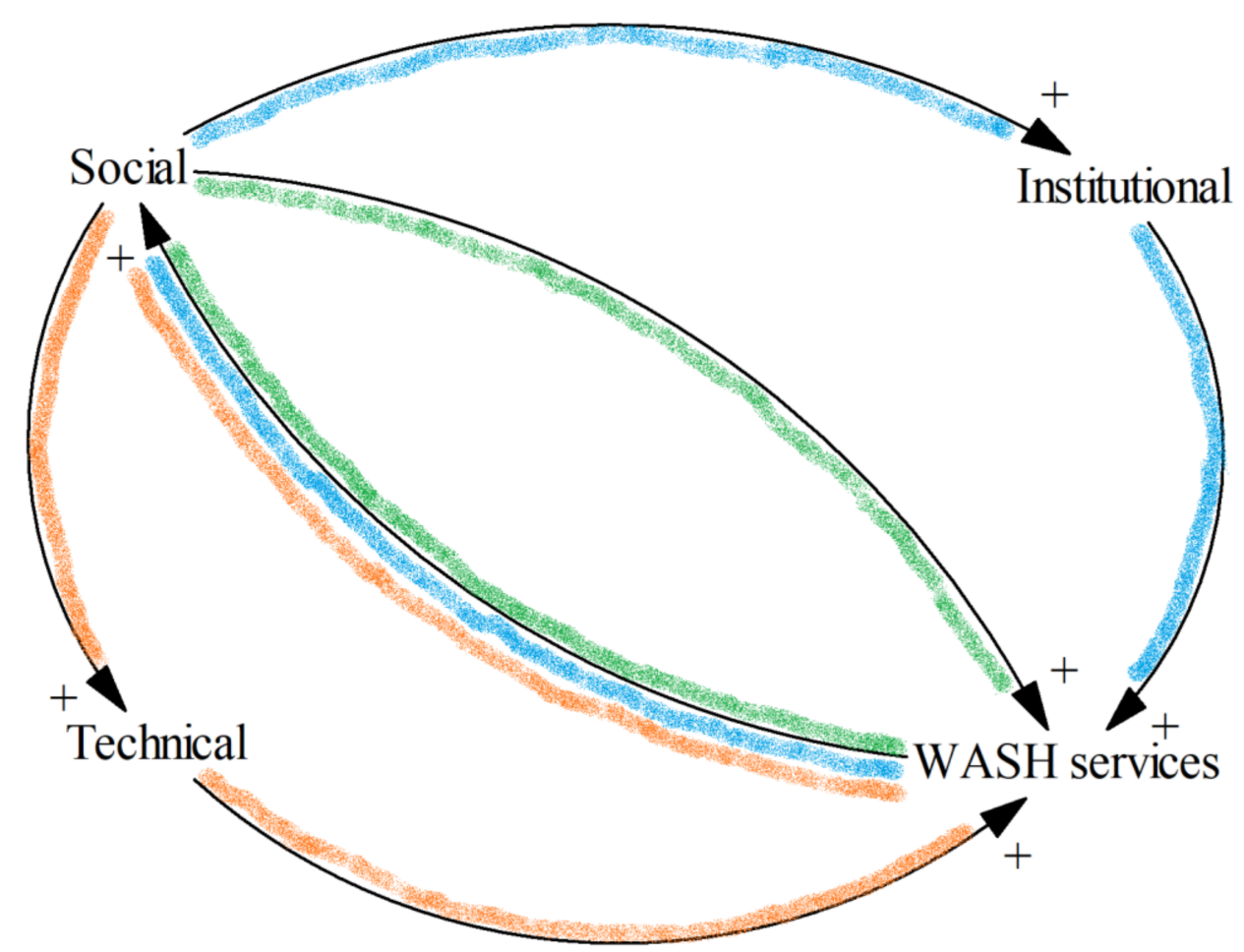

Figure 4. The top three most prominent feedback loops in the system (distinguished by the colour). 


\section{Discussion}

Our results show that the institutional factor is the leverage factor in the WASH services in rural Indonesia. The World Water Assessment Programme (WWAP) report argues that "weak governance is the root cause of failure of water and sanitation operations" which further supports our findings [23]. A previous report also indicates that a country's performance is related to the gap in rural and urban sanitation coverage in that country [24]. This means that it is necessary to strengthen the WASH-related institutions, for example, by capacity building, so they can improve their performance [25-28]. Furthermore, Machado et al. [29] argue that external support is still necessary even though the support should be "gradually withdrawn from the community" so they can do their duties independently.

Despite being the least dependent on other factors, the cross-impact matrix shows that institutional sustainability is highly and positively influenced by two sustainability factors: financial and social factors. It means that strong financial conditions will strengthen the WASH-related institutions, e.g., sufficient funds will facilitate them to perform all their duties [25]. Interestingly, there is one of our respondents gave a score of "-3" on the influence from financial to institutional. The respondent reasons that better financial condition often leads to more corruption and can weaken the institutional foundation within the system, i.e., a negative polarity. The issue of corruption is reported on many occasions in developing countries [30,31], including in Indonesia [32]. However, we agree with the majority of the respondents who believed that, in general, a good financial condition will positively support the WASH-related institutions.

Previous studies mentioned that there is an influence of social aspect on institutional sustainability, especially if we talk about the effects of social culture on the institution's performance [33,34]. They argued that culture is one of the reasons why one institution behaves differently and then generate distinct outcomes than others. For example, workers from a hardworking culture will be highly likely not to be lazy in doing their duties or if someone lives in an open, honest, and transparent culture will be less likely to be corrupt. Another aspect is the organizational culture which results in the performance of the WASHrelated institutions [35]. Hence, we argue that favourable social and cultural conditions will positively influence the WASH-related institution's performance in rural areas.

The feedback loop of Social - WASH appears as the strongest and they are mutually reinforcing, i.e., positively influence each other or bi-directional effect. This means that the accumulation of positive social conditions among the community will increase the sustainability of WASH services. Examples of positive social conditions are a supportive community, positive perceptions or attitudes towards the services, a high sense of ownership, and a high level of community participation [36-39]. On the other hand, sustained and well-functioning WASH services will then influence back the social conditions, e.g., the community is content with the services [40]. Since there is no beginning and endpoint of this feedback loop and the strength of influence between these two are similar, i.e., " 3 " (Table 1), the improvement should be carried out on both simultaneously. A previous sustainability study in the context of water provision reveals that they pay less attention to the social factor even though it influences the sustainability of the service [41].

The second strongest loops are Social — Institutional - WASH services and Social - Technical - WASH services. The influence of social on institutional sustainability, institutional sustainability on WASH services, and then influence back from WASH services to social sustainability has been much discussed in previous paragraphs. For the second loop, we could interpret the influence of social aspect on the technical aspect as the sociocultural acceptability towards the WASH-related technologies, as mentioned in previous studies [42-44]. We argue that if the technology is not culturally accepted, people will not use it or maintain it. Hence, high acceptability by the community results in better technical conditions and then more sustained WASH services.

The variation of responses by the WASH experts, i.e., which comes from different organization and regions, suggests that the relationship between factors is context-specific, as shown in the previous example of the influence from financial to institutional. This may 
also result in different leverage factor in different contexts or locations and we cannot simply apply the same results in all contexts. Therefore, we suggest that, for practical purposes, this kind of study or approach should be conducted among WASH-related stakeholders in a similar area; thus, the results could be applied directly in that area. Visualization of this complexity; i.e., the causal relationships between factors, is also critical for WASH-related stakeholders to understand the conditions in their area and better implement the WASH services or evaluate existing services [45].

This study has limitations related to the methodologies or analyses employed. First, using five sustainability factors may over-simplify the system. Future studies need to incorporate more specific factors or variables in their analysis, although we assume that using FIETS factors are sufficient to get the basic knowledge about the sustainability of WASH services in Indonesia. Second, there is a potential for a misunderstanding of the terms used in the questionnaire. However, we minimized this by conducting pilot surveys among master and $\mathrm{PhD}$ students and providing examples without influencing or directing the respondent's answer. Third, there is a potential for cognitive bias from the values given by the respondents. We minimized this by telling the respondents that the answers have to reflect the actual conditions in their WASH projects. Furthermore, half of the respondents were from NGOs which could results in conflict of interest and also cognitive bias. However, respondents from NGOs have also advantage compared to other stakeholders, e.g., researcher or government. That is because many WASH project in rural Indonesia are conducted by NGOs, meaning that they know well the actual situation in the field. Lastly, having 16 respondents may weaken the confidence in the data collected on the strength of the relationship between variables. Previous studies who have conducted the same approach had 7, 14, and 23 workshop participants or respondents $[18,19,22]$. Nevertheless, more respondents from varied institutional and geographical backgrounds are suggested to have more solid data. Our findings could be seen as a trigger to investigate or confirm the relationships between the sustainability factors, e.g., by using qualitative research in a specific area to support our findings.

\section{Conclusions}

This paper explores the interactions between factors influencing the sustainability of WASH services through the lens of the system dynamics approach. Financial, institutional, environmental, technical, and social sustainability factors were included in the analysis. We found that the improvement of each FIETS factors positively influences other factors and further will sustain the WASH services. The institutional factor was found as the most influential factor in the system, suggesting the need to strengthen the WASH-related institutions in rural areas. Strong financial and social conditions could positively influence the WASH-related institution. Additionally, the feedback loop between WASH services and social factor appears as the most important loop. This portrays the bi-directional effect between these two, i.e., a supportive community will facilitate the sustainability of WASH services and, also, sustained WASH services will result in a more positive attitude of the community towards the WASH services. Furthermore, the relationship between factors is context-specific suggesting we could not simply extrapolate and apply the result in one location into a different context or location. Finally, visualization of the causal relationship between FIETS sustainability factors and WASH services could raise the awareness of all related stakeholders, such as water boards, policymakers, and the community, to better design, implement, and evaluate future or existing WASH services in their area.

Author Contributions: Conceptualization: D.D. (D. Daniel); methodology: D.D. (D. Daniel); software: D.D. (Dennis Djohan); validation: D.D. (D. Daniel) and D.D. (Dennis Djohan); formal analysis: D.D. (Dennis Djohan); investigation: D.D. (Dennis Djohan); resources: D.D. (Dennis Djohan); data curation: D.D. (Dennis Djohan); writing—original draft preparation: D.D. (D. Daniel) and D.D. (Dennis Djohan); writing-review and editing: D.D. (D. Daniel), D.D. (Dennis Djohan) and A.N.; visualization: D.D. (Dennis Djohan); supervision: D.D. (D. Daniel); project administration: D.D. (D. Daniel). All authors have read and agreed to the published version of the manuscript. 
Funding: This research received no external funding.

Institutional Review Board Statement: Ethical review and approval were waived for this study, due to the study does not contain a sensitive issue. Nevertheless, all respondents agreed on participating in this study.

Informed Consent Statement: All respondents agreed on participating in this study.

Data Availability Statement: The raw data can be obtained from the corresponding author.

Acknowledgments: We thank all respondents for their contributions to this study.

Conflicts of Interest: The authors declare no conflict of interest.

\section{References}

1. Cross, P.; Coombes, W.Y.; Norman, R.; Nyarko, K.; Taher, M. Validation of Dutch Wash Alliance Track Record; Wash Alliance International: Haarlem, The Netherlands, 2016.

2. Carrard, N.; Willetts, J. Environmentally sustainable WASH? Current discourse, planetary boundaries and future directions. J. Water Sanit. Hyg. Dev. 2017, 7, 209-228. [CrossRef]

3. Behailu, B.M.; Hukka, J.J.; Katko, T.S. Service Failures of Rural Water Supply Systems in Ethiopia and Their Policy Implications. Public Work. Manag. Policy 2016, 22, 179-196. [CrossRef]

4. Joseph, G.; Andres, L.; Chellaraj, G.; Zabludovsky, J.G.; Ayling, S.C.E.; Hoo, Y.R. Why Do So Many Water Points Fail in Tanzania? An Empirical Analysis of Contributing Factors; Policy Research Working Paper No. 8729; World Bank: Washington, DC, USA, 2019.

5. Kaminsky, J.; Kumpel, E. Dry pipes: Associations between utility performance and intermittent piped water supply in low and middle income countries. Water 2018, 10, 1032. [CrossRef]

6. Hueso, A.; Bell, B. An untold story of policy failure: The Total Sanitation Campaign in India. Water Policy 2013, 15, 1001-1017. [CrossRef]

7. Kimbugwe, C.; Murungu, R.; Watako, D.; Tumisiime, F. Blockages to Service sustainability of Water, Sanitation and Hygiene in Schools. Case study of selected public schools in Kampala Uganda. OIDA Int. J. Sustain. Dev. 2018, 11, 61-72.

8. Asian Development Bank. Leading Factors of Success and Failure in Asian Development Bank Urban Sanitation Projects. 2018. Available online: https://www.adb.org/sites/default/files/evaluation-document/349801/files/tp-urban-sanitation.pdf (accessed on 21 December 2020).

9. Bonsor, H.C.; Oates, N.; Chilton, P.J.; Carter, R.C.; Casey, V.; MacDonald, A.M.; Calow, R.; Alowo, R.; Wilson, P.; Tumutungire, M.; et al. A Hidden Crisis: Strengthening the Evidence Base on the Sustainability of Rural Groundwater Supplies: Results from a Pilot Study in Uganda. 2015. Available online: http:/ /nora.nerc.ac.uk/511071/1/HiddenCrisisFinalReportv7_bgsreview2\%5 Bces\%5D.pdf (accessed on 21 December 2020).

10. Afifah, T.; Nuryetty, M.T.; Musadad, D.A.; Schlotheuber, A.; Bergen, N.; Johnston, R. Subnational regional inequality in access to improved drinking water and sanitation in Indonesia: Results from the 2015 Indonesian National Socioeconomic Survey (SUSENAS). Glob. HealTH Action 2018, 11, 31-40. [CrossRef]

11. UNICEF; WHO. Progress on Household Drinking Water, Sanitation and Hygiene 2000-2017: Special Focus on Inequalities; UNICEF: New York, NY, USA, 2019.

12. Patunru, A.A. Access to safe drinking water and sanitation in Indonesia. Asia Pac. Policy Stud. 2015, 2, 234-244. [CrossRef]

13. Odagiri, M.; Cronin, A.A.; Thomas, A.; Kurniawan, M.A.; Zainal, M.; Setiabudi, W.; Gnilo, M.E.; Badloe, C.; Virgiyanti, T.D.; Nurali, I.A.; et al. Achieving the Sustainable Development Goals for water and sanitation in Indonesia-Results from a five-year (2013-2017) large-scale effectiveness evaluation. Int. J. Hyg. Environ. Health 2020, 230, 113584. [CrossRef]

14. Schweitzer, R.; Grayson, C.; Lockwood, H. Mapping of Water, Sanitation, and Hygiene Sustainability Tools; IRC: The Hague, The Netherlands, 2014. [CrossRef]

15. WASH Alliance International. Accelerating Sustainable WASH; Report 2016; Wash Alliance International: Haarlem, The Netherlands, 2016.

16. Kamulyan, P.; Wiguna, I.P.A.; Slamet, A. Penilaian Keberlanjutan Pengelolaan Sistem Penyediaan Air Minum Berbasis Masyarakat Di Kota Blitar. J. Civ. Eng. 2018, 32, 60. [CrossRef]

17. Trisnanto, A. Sanitasi di Indonesia Timur: Keberlanjutan dan Inovasi Kebijakan, 1st ed.; UB Press: Malang, Indonesia, 2017.

18. Valcourt, N.; Walters, J.; Javernick-Will, A.; Linden, K.G.; Hailegiorgis, B. Understanding rural water services as a complex system: An assessment of key factors as potential leverage points for improved service sustainability. Sustainability 2020, $12,1243$. [CrossRef]

19. Walters, J.P.; Neely, K.; Pozo, K. Working with complexity: A participatory systems-based process for planning and evaluating rural water, sanitation and hygiene services. J. Water Sanit. Hyg. Dev. 2017, 7, 426-435. [CrossRef]

20. Peters, D.H. The application of systems thinking in health: Why use systems thinking? Health Res. Policy Syst. 2014, 12, 1-6. [CrossRef] [PubMed]

21. Vensim Pro, version 8.1; Ventana Systems: Harvard, MA, USA, 2020.

22. Walters, J.P.; Javernick-Will, A.N. Long-term functionality of rural water services in developing countries: A system dynamics approach to understanding the dynamic interaction of factors. Environ. Sci. Technol. 2015, 49, 5035-5043. [CrossRef] [PubMed] 
23. WWAP. The United Nations World Water Development Report 2019: Leaving no One Behind; UNESCO: Paris, France, 2019.

24. Cronk, R.; Luh, J.; Meier, B.M.; Bartram, J. The WASH Performance Index Report; University of North Carolina (UNC); Gillings School of Global Public Health; The Water Institute, Conrad N. Hilton Foundation: Chapel Hill, NC, USA, 2015; Available online: http:/ / waterinstitute.unc.edu/wash-performance-index-report/ (accessed on 19 January 2021).

25. Hutchings, P.; Chan, M.Y.; Cuadrado, L.; Ezbakhe, F.; Mesa, B.; Tamekawa, C.; Franceys, R. A systematic review of success factors in the community management of rural water supplies over the past 30 years. Water Policy 2015, 17, 963-983. [CrossRef]

26. Kativhu, T.; Mazvimavi, D.; Tevera, D.; Nhapi, I. Implementation of Community Based Management (CBM) in Zimbabwe: The dichotomy of theory and practice and its influence on sustainability of rural water supply systems. Phys. Chem. Earth 2018, 106, 73-82. [CrossRef]

27. Ferrero, G.; Setty, K.; Rickert, B.; George, S.; Rinehold, A.; Defrance, J.; Bartram, J. Capacity building and training approaches for water safety plans: A comprehensive literature review. Int. J. Hyg. Environ. Health 2019, 222, 615-627. [CrossRef]

28. Borja-Vega, C.; Pena, L.; Stip, C. Sustainability of rural water systems: Quantitative analysis of Nicaragua's monitoring data. Waterlines 2017, 36, 40-70. [CrossRef]

29. Machado, A.; Dos Santos, J.A.N.; Quindeler, N.; Alves, L.M.C. Critical Factors for the Success of Rural Water Supply Services in Brazil. Water 2019, 11, 2180. [CrossRef]

30. Davis, J. Corruption in public service delivery: Experience from South Asia's water and sanitation sector. World Dev. 2004, 32, 53-71. [CrossRef]

31. Pusok, K. Public-Private Partnerships and Corruption in the Water and Sanitation Sectors in Developing Countries. Political Res. Q. 2016, 69, 678-691. [CrossRef]

32. Arismaya, A.D.; Utami, I. Facts, causes and corruption prevention: Evidence in Indonesian ministries. J. Contemp. Account. 2019, 1, 65-84. [CrossRef]

33. Pande, S.; Roobavannan, M.; Kandasamy, J.; Sivapalan, M.; Daniel, D.; Lyu, H.; Rietveld, L. A Socio-Hydrological Perspective on the Economics of Water Resources Development and Management. Available online: https://oxfordre.com/ environmentalscience/view/10.1093/acrefore/9780199389414.001.0001/acrefore-9780199389414-e-657 (accessed on 6 May 2020).

34. Tabellini, G. Culture and Institutions: Economic Development in the Regions of Europe. J. Eur. Econ. Assoc. 2010, 8, 677-716. [CrossRef]

35. Summerill, C.; Pollard, S.J.T.; Smith, J.A. The role of organizational culture and leadership in water safety plan implementation for improved risk management. Sci. Total Environ. 2010, 408, 4319-4327. [CrossRef] [PubMed]

36. Marks, S.J.; Komives, K.; Davis, J. Community participation and water supply sustainability: Evidence from handpump projects in rural Ghana. J. Plan. Educ. Res. 2014, 34, 276-286. [CrossRef]

37. Daniel, D.; Sirait, M.; Pande, S. A hierarchical Bayesian Belief Network model of household water treatment behaviour in a suburban area: A case study of Palu-Indonesia. PLoS ONE 2020, 15, e0241904. [CrossRef] [PubMed]

38. Contzen, N.; Marks, S.J. Increasing the regular use of safe water kiosk through collective psychological ownership: A mediation analysis. J. Environ. Psychol. 2018, 57, 45-52. [CrossRef]

39. Bhandari, B.; Grant, M. User satisfaction and sustainability of drinking water schemes in rural communities of Nepal. Sustain.: Sci. Pract. Policy 2007, 3, 12-20. [CrossRef]

40. Ellawala, K.C.; Priyankara, D.P.M.P. Consumer satisfaction on quantity and quality of water supply: A study in Matara, Southern Sri Lanka. Water Pract. Technol. 2016, 11, 678-689. [CrossRef]

41. Iribarnegaray, M.A.; D'Andrea, M.L.G.; Rodriguez-Alvarez, M.S.; Hernández, M.E.; Brannstrom, C.; Seghezzo, L. From indicators to policies: Open sustainability assessment in the water and sanitation sector. Sustainability 2015, 7, 14537-14557. [CrossRef]

42. Ahmed, S.K.; Ahmed, S.S. Socio-cultural acceptability of urine diverted composting toilets: A review of literature for possible adoption in peri-urban areas as a sustainable sanitation solution. AIP Conf. Proc. 2017, 1919, 020043.

43. Wasonga, J.; Okowa, M.; Kioli, F. Sociocultural Determinants to Adoption of Safe Water, Sanitation, and Hygiene Practices in Nyakach, Kisumu County, Kenya: A Descriptive Qualitative Study. J. Anthropol. 2016, 2016, 1-5. [CrossRef]

44. Emmanuel, M.; Saravanan, V. Water Supply and Sanitation Practices in Nigeria: Applying Local Ecological Knowledge to Understand Complexity; University of Bonn: Bonn, Germany, 2012; Available online: https:/ / www.econstor.eu/bitstream/10419/88399/1/77 3377492.pdf (accessed on 21 December 2020).

45. Kinchin, I.M.; Streatfield, D.; Hay, D.B. Using Concept Mapping to Enhance the Research Interview. Int. J. Qual. Methods 2010, 9, 52-68. [CrossRef] 